\title{
Tangence
}

\section{La recherche de la petite bête noire (À tout prix. Les prix littéraires au Québec, de Robert Yergeau)}

\section{Patrick Guay}

Numéro 49, décembre 1995

Les littératures francophones de l'Afrique et des Antilles

URI : https://id.erudit.org/iderudit/025886ar

DOI : https://doi.org/10.7202/025886ar

Aller au sommaire du numéro

Éditeur(s)

Tangence

ISSN

0226-9554 (imprimé)

1710-0305 (numérique)

Découvrir la revue

Citer ce compte rendu

Guay, P. (1995). Compte rendu de [La recherche de la petite bête noire (À tout prix. Les prix littéraires au Québec, de Robert Yergeau)]. Tangence, (49),

131-132. https://doi.org/10.7202/025886ar 


\section{La recherche de la petite bête noire \\ Robert Yergeau, $\dot{A}$ tout prix. Les prix littéraires au Québec, Montréal, Triptyque, 1994.}

Les prix littéraires ne sont pas très nombreux au Canada français [...]

Adrien Thério, Livres et auteurs canadiens, 1961

Le récent ouvrage de Robert Yergeau trace un portrait nettement sombre de l'institution littéraire québécoise, qui a bien changé depuis le temps où le responsable de Livres et auteurs canadiens déplorait l'absence de reconnaissance accordée aux écrivains d'ici. Ces essais polémiques sont redevables aux travaux de Pierre Bourdieu, dont Yergeau se réclame, et dont la trace se fait sentir, parfois, jusque dans la façon de tourner la phrase.

Pour cette raison, peut-être, et pour certaines autres, dont je fais état à l'instant, il y a peu à dire du contenu de $A$ tout prix. Dans le meilleur des cas, c'est du Bourdieu bien appris et plutôt bien appliqué, c'est-à-dire à la lettre; dans le pire, ce sont des conclusions faussement dérangeantes, des étonnements tout aussi étonnants, sinon plus, que leur objet: sa surprise, par exemple, de voir les membres des jurys des prix du gouverneur général recrutés parmi les professeurs, universitaires ou collégiaux, les écrivains, journalistes et autres gens du "milieu" du livre et de l'enseignement (Yergeau reprend à Réginald Martel l'expression de "mafia universitaire")! À quand, suis-je tenté de de demander, les techniciens en soins infirmiers jurys des prix David, Desjardins et autres? On voit où peut mener le besoin de traquer, à tout prix, la petite bête noire. $\dot{A}$ tout prix, ce sont encore des dégoûts mal déguisés, de petites haines à peine dissimulées. Son ressentiment à l'endroit de Miron est tel qu'il n'y a rien que celuici ait fait, dit ou écrit qui ne résiste à l'examen. On ne peut nier que l'attitude et les propos des Miron, Beausoleil, Archambault et autres habitués des prix soient parfois paradoxaux. Yergeau aurait pu sonder ce paradoxe, qu'il se contente ici de dénoncer. Il frôle, soit dit en passant, la mauvaise foi quand il détourne certains propos, faisant à l'accusé un procès d'intention: de Miron 
qui, recevant le prix machin, signale sa dette envers tous les hexagoniens, Yergeau écrit: "recevoir un prix au nom de tous, comme si, en personne, il réunissait tous les écrivains de son temps! (p. 104). Dans l'ensemble, la démonstration est le plus souvent inutilement longue, étant donné la clarté de l'entreprise ("mettre au jour certains jeux relationnels").

Je me garderai bien de dire que Yergeau a tort sur toute la ligne. Prises à la pièce, certaines observations tiennent. Mais nulle part n'apparaîr le moindre début d'explication sur la façon dont les pouvoirs, symbolique et économique, changent de main. Rapidement, toutes ces énumérations de prix reçus, de noms et de dates lassent.

En revanche, le projet même de l'auteur, son caractère scientifique et non son aspect anecdotique, les questions d'ordre épistémologique qu'il soulève, ont retenu mon attention et auraient pu faire l'objet d'une brève réflexion. Pour dire les choses simplement: comment peut-on parler de l'intérieur du système? Comment peut peut-on étudier un objet dont on est soi-même partie prenante? Cette question n'est pas neuve, que d'aucuns brandissent comme un reproche à l'endroit du sociologue, de formation ou de salon. Yergeau, professeur, poète, lauréat, devrait s'interroger sur ce fait pour le moins problématique: le lieu dont il parle est celui-là même d'où il parle, et évaluer, conséquemment, la relativité de ses propres propos. De quelle illusion l'auteur d'À tout prix est-il lui-même "victime", consentante ou non? Bien entendu, la forme même adoptée par Yergeau, l'essai, peut expliquer l'absence de toute considération de cet ordre.

Je ne prétends nullement que le sociologue, le chercheur ne doit pas prendre position. La chose me paraît même inévitable (elle est peut-être souhaitable). Mais je suis tenté de dire, avec Lucien Goldmann, qu'، une des tâches les plus importantes pour tout chercheur sérieux nous semble résider dans l'effort pour connaître et faire connaitre aux autres ses valorisations en les indiquant explicitement [...]". Robert Yergeau n'a fait ni l'un ni l'autre. 